\title{
CONTABILIDADE DE CUSTOS E RESULTADO ECONÔMICO: UMA ABORDAGEM DA GERAÇÃO DE VALOR PARA A SOCIEDADE À LUZ DOS INDICADORES DE GESTÃO DO IFRN
}

\author{
M. A. SILVA, P. T. S. BRAGA e E. M. P. SILVA \\ Instituto Federal de Educação, Ciência e Tecnologia do Rio Grande de Norte \\ marcostce@bol.com.br
}

Artigo submetido em novembro/2015 e aceito em dezembro/2015

DOI: 10.15628/empiricabr.2015.3831

\section{RESUMO}

Ao relacionar o resultado econômico e os indicadores de gestão do IFRN, esta pesquisa teve por objetivo verificar quais indicadores de gestão têm influência significativa no resultado econômico dessa instituição. Para responder à questão de pesquisa, foram utilizados os indicadores de gestão e os resultados econômicos de 15 campi do IFRN referentes ao período de 2011 e 2012. Após a coleta dos dados, o passo seguinte foi submetêlos a tratamento estatístico, por meio da técnica de regressão múltipla com dados em painel, tratados por meio do método Mínimos Quadrados Ordinários. Baseado no procedimento estatístico, verificou-se que, dos 10 (dez) indicadores de gestão utilizados na pesquisa, 5 (cinco) deles demonstraram ser influentes no resultado econômico de forma significativa a $1 \%$ e
$5 \%$, quais sejam: Relação de Concluintes por Alunos Matriculados (RC/A), Relação Alunos por Docente em Tempo Integral (RA/DTI), Percentual de Gastos com Pessoal (PGP), Percentual de Gastos com Outros Custeios (PGOC) e Índice de Titulação do Corpo Docente (ITCD). Com exceção do RA/DTI, que demonstrou uma relação direta com o resultado econômico, todos os outros se relacionam de forma inversa com a variável dependente. Nesse caso, sempre que ocorre uma alteração para mais nesses indicadores, o resultado econômico diminui. A pesquisa também gerou informações sobre o resultado econômico dos campi, os quais, à exceção do campus Educação a Distância (EaD), tiveram resultado econômico negativo.

PALAVRAS-CHAVE: Indicadores de Gestão. Resultado Econômico. Custos.

\section{KNOWLEDGE EXTRACTION FROM TEXTUAL SOURCES: AN EXPLORATORY STUDY ON THE SUSTAINABILITY DOMAIN}

\begin{abstract}
This research used management indicators and economic outcomes of 15 IFRN campi for the period from 2011 and 2012. After the data collect, the next step was to subject them to statistical analysis in the specific case the technique of multiple regression with panel data, processed through the OLS method. Based on the statistical procedure, it was found that the 10 (ten) management indicators used in the study, 5 (five) of them: List of Graduates by Enrollment (RC/A), Student/Full-Time professor Relation (RA/DTI), Percentage of Staff Costs (PGP), percentage of Expenditures on other Costing (PGOC) and Titration Faculty index (ITCD). They proved influential in economic outcome, significantly at $1 \%$ and $5 \%$. Except RA/DTI, which demonstrated a direct relationship with the Economic Outcome, all others relate inversely with
\end{abstract}

the dependent variable. In this case, whenever a change occurs in these economic indicators, the result decreases. The survey yielded information on the campi economic outcome, which it found that the, exception campus Distance Education (DE), all others had negative economic profit. This situation has probable cause the fact that many campi are in the process of expansion and part of them are active recently. 


\section{INTRODUÇÃO}

A administração pública vem passando por constantes mudanças no tocante à eficiência, eficácia e transparência dos gastos públicos. Os gestores são cada vez mais cobrados, pela sociedade e instituições fiscalizadoras, a darem satisfação de seus atos e de como estão gerenciando os recursos públicos. No Brasil, o controle nos gastos públicos teve um grande avanço a partir de 1986, com a criação da Secretaria do Tesouro Nacional (STN) (FERREIRA, 2006).

A partir das transformações sofridas pela administração pública, principalmente com o advento da nova gestão pública, as exigências sobre a gestão dos gastos públicos evoluíram para muito além do controle orçamentário: é preciso que o gestor gerencie a instituição pública, objetivando sempre o melhor resultado possível em cada ação desenvolvida.

O conhecimento dos custos no setor público é fundamental para atingir uma alocação eficiente de recursos e, consequentemente, gerar valor para a sociedade por meio de suas atividades. Com a informação detalhada dos custos por setor, produtos e serviços, poderá ser possível identificar os gastos e responsabilizar pessoas, em decorrência de suas ações e decisões, pelo resultado obtido na gestão dos recursos públicos.

Conforme Maus e Souza (2008), a gestão pública por resultados é o caminho que pode levar o gestor a atingir seus objetivos de forma eficiente e eficaz. Essa é a mesma preocupação do Programa Nacional de Gestão Pública e Desburocratização (BRASIL, 2005), instituído pelo Governo Federal por meio do Decreto no 5.378/2005, que tem como objetivo a promoção da gestão pública de excelência (BRASIL, 2005).

Slomski et al. (2010) explica que o valor adicionado nas organizações públicas consiste na diferença entre a receita de oportunidade econômica, produzida com a prestação do serviço entregue, e o custo de produção para realização do serviço.

Nesse contexto, os indicadores de gestão podem exercer uma função importante a partir do momento que possibilitam ao gestor evidenciar os elementos que influenciaram nos resultados da gestão, e verificar se esses resultados estão em sintonia com o planejamento elaborado para determinado período.

De posse de informações estratégicas, como os indicadores de gestão e o resultado econômico, a administração pública poderá ter melhores condições para acompanhar e avaliar o desempenho da gestão.

A educação pública, por exemplo, é uma área que tem grandes desafios para serem superados, dentre eles está a falta de recursos para poder atender às demandas da sociedade. 
Para D’Amoré (2006), o sistema escolar é um sistema aberto que precisa de recursos para sua sobrevivência. Esses recursos são processados para a geração de resultados como: melhoria do nível cultural da população e aperfeiçoamento dos indivíduos, tudo isso ao menor custo possível.

Não diferentemente, as entidades educacionais públicas, como universidades e institutos federais, por serem autarquias, devem obedecer aos princípios da gestão pública, assim como preocupar-se com o alcance dos objetivos citados anteriormente.

Para melhor esclarecer essas sistemáticas é que este trabalho se propôs a evidenciar, se existe significância estatística entre os custos, as receitas econômicas e os indicadores de gestão dos campi do Instituto Federal de Educação, Ciência e Tecnologia do Rio Grande do Norte (IFRN), no período de 2011 e 2012. Para isso, buscou-se resposta à seguinte pergunta: quais indicadores de gestão do IFRN exercem influência significativa na formação do seu resultado econômico? Para responder a essa questão é que essa pesquisa procurou identificar os indicadores de gestão do IFRN que exercem influência significativa na formação do seu resultado econômico.

\section{REFERENCIAL TEÓRICO}

\subsection{Contabilidade de custos no setor público}

Dutra (2010) ressalta que a contabilidade de custos é o ramo da contabilidade que se dedica a produzir informações para os vários níveis gerenciais de uma entidade, como apoio às funções de determinação de desempenho, de planejamento e controle das operações e de tomadas de decisões.

Para Hansen e Mowen (2009), as informações de custo são utilizadas para tomada de decisão interna e externa, mensuração e monitoramento de desempenho em todos os níveis da empresa, medindo e analisando a lucratividade por meio da alocação de custos às atividades e produtos utilizados no processo organizacional.

A contabilidade de custos do setor público, no Brasil, já é exigida por algumas normas, como a Lei $n$ o 4.320/1964 e a LRF (2000). Mas, mesmo com a obrigação legal, o Sistema de Informações de Custos no Setor Público (SICSP) é pouco utilizado na gestão dos recursos. A contabilidade de custos serve de base para mensurar a eficiência da gestão pública (SOUZA et al., 2011).

Para Honda (2011), a contabilidade de custos deve gerar informações para diferentes níveis gerenciais de uma instituição e auxiliar no processo de planejamento, orçamento, execução, avaliação e controle das operações públicas. Com acesso a tais informações, a população e os órgãos de controle podem monitorar e mensurar a eficiência e economicidade da atividade pública. 
Para Holanda e Machado (2010), a mensuração e o controle dos custos permitem ao gestor saber quanto custa produzir cada um dos bens ou serviços públicos, o que dará a ele fundamentos para decidir pela alternativa mais vantajosa para a sociedade.

\subsection{Administração pública por resultados}

Diniz, Dieng e Moraes (2008, p. 4) consideram que "a administração pública gerencial surgiu como mais uma alternativa ao processo evolutivo da organização do Estado, na busca da eficiência e eficácia na aplicação regular dos recursos públicos".

Gestão pública é um termo que indica utilização de práticas novas na administração das instituições públicas, algumas importadas do setor privado, outras desenvolvidas nas últimas décadas. Seguindo essa nova tendência de administrar os gastos públicos é que surge a administração pública por resultados.

O Gespública, programa instituído pelo governo federal e que tem como objetivo a promoção e o desenvolvimento da gestão pública de excelência, está voltado para uma administração pública de resultados (BRASIL, 2012). Por meio do Modelo de Excelência na Gestão Pública (MEGP), o governo pretende aprimorar os processos na administração pública de tal forma que eles permitam que a administração chegue a resultados desejados e adequados para toda sociedade.

São vários os conceitos a serem implantados pelo MEGP e utilizados na administração pública, dentre eles, pode-se citar os dois mais sintonizados com esta pesquisa: a orientação por processos de informações, que objetiva orientar a tomada de decisões e execução das ações, sempre com base na medição e análise do desempenho, de acordo com as informações disponíveis; e a geração de valor, que procura alcançar resultados consistentes, assegurando o aumento de valor para todos os interessados (BRASIL, 2005).

Catelli (2001) explica que a medida de valor é dada pelo mercado, e que o governo agrega valor por meio de suas ações quando o valor de seus benefícios são superiores aos recursos consumidos. De acordo com Slomski (2009) o resultado econômico é a diferença entre a receita econômica, relacionada ao programa para benefício da sociedade, e o custo de execução do programa. O mesmo autor assevera que um resultado negativo representa um indicador da ineficiência do administrador no processo de gestão. Nesse caso, estará ocorrendo a destruição de valor.

Barcelos, Sobral e Lustosa (2005) destacam que a criação de valor pelos órgãos governamentais pode variar, dependendo de quem percebe a geração do benefício. Esta pesquisa considera o resultado econômico do Instituto Federal do Rio Grande do Norte como uma medida que indica se a gestão gerou valor econômico para a sociedade, quando ocorre superávit, ou se destruiu valor, no caso do resultado expressar déficit.

Como forma de medição do valor econômico gerado pelo IFRN, a pesquisa se utilizou da Demonstração do Resultado Econômico (DRE). De acordo com a Resolução CFC 
no 1.133/2008 (CFC, 2008c), o objetivo da Demonstração do Resultado Econômico é evidenciar o resultado econômico das ações do setor público, considerando sua interligação com o subsistema de custos. De acordo com a NBC T.16.6 (CFC, 2008c), a Demonstração do Resultado Econômico, que é elaborada de forma facultativa, tem como premissas os seguintes conceitos:

- Custo de Oportunidade (CO) - valor que seria desembolsado na alternativa desprezada de menor valor entre aquelas consideradas possíveis para a execução da ação pública;

- Receita Econômica (RE) - valor apurado a partir de benefícios gerados à sociedade pela ação pública, obtido por meio da multiplicação da quantidade de Serviços Prestados $(\mathrm{N})$, bens ou produtos fornecidos, pelo Custo de Oportunidade (CO), daí: RE $=\mathrm{N} \times \mathrm{CO}$;

- Custo de Execução (CE) - valor econômico despendido pela entidade na ação objeto da apuração do resultado econômico. É dividido em custos diretos e indiretos.

O resultado econômico apurado (REA) pode ser considerado o incremento líquido de benefícios para a sociedade a partir de decisões e atitudes eficientes e eficazes do gestor público, calculado a partir da diferença entre a Receita Econômica (RE) e o Custo de Execução (CE) da ação, de acordo com a Equação 1 a seguir:

$$
R E A=R E-C E \text { ou } R E A=(N \times C O)-C E
$$

A DRE deve ser elaborada considerando sua interligação com o subsistema de custos.

Quadro 1: Demonstração do Resultado Econômico

\begin{tabular}{|c|c|c|}
\hline Especificação & $\begin{array}{c}\text { Exercício } \\
\text { atual }\end{array}$ & $\begin{array}{c}\text { Exercício. } \\
\text { anterior }\end{array}$ \\
\hline $\begin{array}{l}\text { 1. Receita econômica dos serviços prestados e dos bens ou produtos fornecidos } \\
\text { 2. (-) Custos diretos identificados com a execução da ação pública } \\
\text { 3. (=) Margem bruta } \\
\text { 4. (-) Custos indiretos identificados com a execução da ação pública }\end{array}$ & & \\
\hline 5. (=) Resultado Econômico Apurado & & \\
\hline
\end{tabular}

Fonte: Brasil (2012).

A Demonstração do Resultado Econômico está intimamente relacionada ao sistema de informação de custos (SIC). A Resolução CFC no 1.129/2008 aprovou a NBC T 16.2 (CFC, 2008b), que trata de patrimônio e sistemas contábeis, estabelece que o subsistema de custos tem como objetivo registrar, processar e evidenciar os custos dos bens e serviços produzidos e ofertados à sociedade pela entidade pública. Ao atingir seu objetivo, o subsistema de custos gera informações necessárias à elaboração da DRE. 


\subsection{Eficiência, eficácia e efetividade no setor público}

A eficiência, a eficácia e a efetividade são parâmetros que servem para medir o desempenho e, consequentemente, o resultado de uma gestão.

A eficiência está relacionada aos rendimentos dos insumos aplicados na prestação de serviços ou por meio dos bens disponibilizados. Ela pode ser medida pela relação dos recursos empregados e os resultados obtidos (GNISCl, 2010). Moraes (2007) explica que eficiência na administração é fazer as coisas da forma correta, utilizando os recursos a sua disposição da melhor maneira possível.

Segundo Bio (2008), uma empresa eficiente é aquela que consegue o seu volume de produção com o menor dispêndio possível de recursos, o que se traduzirá em um menor custo por unidade produzida.

De acordo com Brasil (2009), a efetividade está relacionada ao alcance dos objetivos finais, isto é, refere-se ao alcance dos efeitos esperados sobre a sociedade. A efetividade pode ser entendida como o alcance de eficiência e eficácia ao mesmo tempo. De acordo com Gomes (2009), a efetividade é considerada como a produção de impactos esperados. Ela está relacionada a uma alteração no ambiente, é um conceito mais amplo que o de eficácia e ambas são avaliadas por meio de indicadores.

De acordo com o Guia Referencial para Medição de Desempenho (GRMD) e Manual para Construção de Indicadores (BRASIL, 2009), os indicadores possuem, pelo menos, duas funções básicas, que consistem em: descrever, por meio da geração de informações, o estado real dos acontecimentos e o seu comportamento; e analisar as informações presentes com base nas anteriores de forma a realizar proposições valorativas. Os indicadores não refletem apenas números, mas também atribuições de valor que medem o desempenho da gestão por meio de aplicação de critérios de avaliação, como eficiência, eficácia e efetividade.

De acordo com Bittencourt (2006, p. 15), os indicadores de desempenho são "aproximações à realidade multidimensional da gestão" e fornecem "uma boa visão acerca do resultado que se deseja medir".

É preciso entender o que se pretende com a utilização de indicadores no processo de gestão, para não correr o risco de se querer medir tudo e acabar não medindo nem o mínimo necessário. De acordo com o Guia de Referencial para Medição de Desempenho (BRASIL, 2009), as utilidades dos indicadores são as relacionadas no Quadro 2.

Quadro 2: Utilidade dos indicadores de gestão

\begin{tabular}{|c|l|}
\hline Sequência & \multicolumn{1}{c|}{ Descrição das utilidades } \\
\hline 1 & Mensurar os resultados e gerir o desempenho \\
\hline 2 & Embasar a análise crítica dos resultados obtidos e do processo de tomada de decisão \\
\hline
\end{tabular}




\begin{tabular}{|l|l|}
3 & Contribuir para a melhoria contínua dos processos organizacionais \\
\hline 4 & Facilitar o planejamento e o controle do desempenho \\
\hline 5 & $\begin{array}{l}\text { Viabilizar a análise comparativa do desempenho da organização e do desempenho de } \\
\text { diversas organizações atuantes em áreas ou ambientes semelhantes }\end{array}$ \\
\hline
\end{tabular}

Fonte: Brasil (2009).

\subsubsection{Rede Federal de Educação Profissional}

A Lei no 11.892/2008 instituiu a Rede Federal de Educação Profissional, Científica e Tecnológica e, sendo assim, a responsabilidade pela supervisão das unidades de forma a apoiar e monitorar suas ações ficou a cargo da Secretaria de Educação Profissional e Tecnológica (SETEC).

De 2002 a 2010, a Rede Federal de Educação Profissional e Tecnológica passou de 140 para 354 unidades, devido aos planos de expansão. Com eles, no período de 2011 a 2014, pretende-se atingir o número de 562 unidades na rede, conforme Manual para Produção e Análise dos Indicadores da Rede Federal (2012).

Hoje, o IFRN possui dezesseis campi, e até no segundo semestre de 2013, inaugurou mais três unidades. Esses campi fazem parte do processo de expansão.

Com a expansão da Rede Federal de Educação, alcançando as diversas regiões do país, faz-se necessária a construção e ampliação de medidas de desempenho com objetivo de acompanhar em que condições essa ampliação de ofertas de vagas está sendo efetivada, com vistas a identificar o impacto na qualidade dos serviços oferecidos pelas instituições de ensino. Objetivando suprir à necessidade de avaliação, foram estabelecidos, no Acórdão TCU no 2.267/2005, 12 indicadores para avaliar a eficiência e eficácia dos Institutos Federais de Ensino.

O IFRN anualmente elabora e publica em seu sítio o relatório de gestão, que é apresentado aos órgãos de controle interno e externo como prestação de contas dessa instituição. O relatório de gestão tem como objetivo principal apresentar o desempenho da gestão do IFRN, e sua elaboração é orientada por instruções normativas e portarias emitidas pelo Tribunal de Contas da União (TCU). 
Quadro 3: Indicadores de gestão - Acórdão TCU no 2.267/2005

\begin{tabular}{|c|c|c|}
\hline & Indicadores & Fórmula de Cálculo \\
\hline \multirow{6}{*}{ Acadêmicos } & Relação Candidato/Vaga & $\mathrm{RC} / \mathrm{V}=\frac{\text { Número de Inscrições }}{\text { Vagas ofertadas }}$ \\
\hline & Relação Ingressos/Aluno & $\mathrm{RI} / \mathrm{A}=\frac{\text { Número de Ingressos }}{\text { Alunos Matriculados/EP }} x 100$ \\
\hline & Relação Concluintes/Aluno & $\mathrm{RC} / \mathrm{A}=\frac{\text { Número de Concluintes }}{\text { Alunos Matriculados/EP }} \times 100$ \\
\hline & $\begin{array}{l}\text { Índice de Eficiência Acadêmica - } \\
\text { Concluintes }\end{array}$ & $\begin{array}{c}\mathrm{IEAC}=\left(\sum \text { Concluintes } / \sum \text { Ingressos }\right. \\
\text { correspondentes }) \times 100\end{array}$ \\
\hline & Índice de Retenção do Fluxo Escolar & $\mathrm{RFE}=\frac{\text { Retenção }}{\text { Alunos Matriculados/EP }} \times 100$ \\
\hline & $\begin{array}{l}\text { Relação de Alunos/Docente em Tempo } \\
\text { Integral }\end{array}$ & $\mathrm{RA} / \mathrm{DTI}=\frac{\text { Alunos Matriculados/EP }}{\text { Docentes em tempointegral }}$ \\
\hline & Gastos Correntes por Aluno & $\mathrm{GCA}=\frac{\text { Total de Gastos Correntes }}{\text { Alunos matriculados/EP }}$ \\
\hline Administrativos & Percentual de Gastos com Pessoal & PGP $=\frac{\text { Total de Gastos com Pessoal }}{\text { Gastos Totais }} \times 100$ \\
\hline 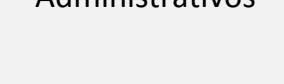 & Percentual de Gastos com outros Custeios & PGOC $=\frac{\text { Outros Custeios }}{\text { Gastos Totais }} \times 100$ \\
\hline & Percentual de Gastos com Investimentos & $\begin{array}{l}\text { PGI=(Total de Gastos com Investimentos e } \\
\text { Inversões financeiras/Gastos Totais) x100 }\end{array}$ \\
\hline Socioeconômico & $\begin{array}{l}\text { Número de Alunos Matriculados por Renda } \\
\text { per Capita Familiar }\end{array}$ & $\begin{array}{c}\text { PSEC = Alunos Matriculados/EP por classe } \\
\text { de renda familiar per capita }\end{array}$ \\
\hline Gestão de Pessoas & Índice de Titulação do Corpo Docente & $\mathrm{ITCD}=\frac{\mathrm{G} \times 1+\mathrm{A} \times 2+\mathrm{E} \times 3+\mathrm{M} \times 4+\mathrm{D} \times 5}{\mathrm{G}+\mathrm{A}+\mathrm{E}+\mathrm{M}+\mathrm{D}}$ \\
\hline
\end{tabular}

Fonte: IFRN (2012).

Os indicadores descritos no Quadro 3 são elaborados anualmente por cada campus do IFRN e uma versão consolidada, de todo instituto, é publicada no relatório de gestão.

\section{PROCEDIMENTOS METODOLÓGICOS}

Esta pesquisa se caracteriza como sendo um estudo de caso, que, segundo Gil (2010), é o estudo aprofundado e exaustivo de um ou de poucos objetos, de maneira a permitir conhecimentos amplos e detalhados dos mesmos. A pesquisa foi realizada nos campi do IFRN e teve, dentre os objetivos específicos, o de efetuar o levantamento de informações necessárias para a elaboração da Demonstração do Resultado Econômico e calcular os indicadores de gestão de cada campus do IFRN. 


\subsection{Instrumentos de coleta e tratamento dos dados}

A população analisada neste estudo foi representada pelos campi do IFRN que estavam em atividades nos anos de 2011 e 2012. A amostra correspondeu ao total da população, que representou 16 campi. Dentre esses campi, o campus Natal Central foi excluído da amostra, por se tratar de um outlier, uma vez que o gráfico Box-plot evidencia uma disparidade muito alta entre os valores das variáveis do campus Natal Central em relação aos demais campi.

Como forma de planejar o momento do levantamento dos dados, inicialmente foi elaborada uma planilha com a relação de todos os dados que seriam coletados para utilização na pesquisa.

Quadro 4: Componentes da variável dependente (RE)

\begin{tabular}{|l|c|c|c|}
\hline Dados a serem coletados durante a pesquisa & \multicolumn{2}{|c|}{ Período } & Campus \\
\hline Alunos matriculados por curso e por campus & 2011 & 2012 & Todos \\
\hline $\begin{array}{l}\text { Valor das mensalidades de cada curso do IFRN em escolas da rede privada de } \\
\text { ensino no Rio Grande do Norte }\end{array}$ & 2011 & 2012 & Todos \\
\hline Despesas correntes liquidadas & 2011 & 2012 & Todos \\
\hline Despesas com material de consumo liquidadas & 2011 & 2012 & Todos \\
\hline Despesas com pessoal liquidadas & 2011 & 2012 & Todos \\
\hline Relatório de saídas de material de consumo do almoxarifado & 2011 & 2012 & Todos \\
\hline Valor contábil dos Imóveis de cada campus & 2011 & 2012 & Todos \\
\hline Valor contábil dos móveis por campus & 2011 & 2012 & Todos \\
\hline Vida útil dos bens móveis e imóveis & 2011 & 2012 & Todos \\
\hline
\end{tabular}

Fonte: Elaboração própria.

A seguir, o Quadro 5, que trata dos elementos das variáveis preditivas.

Quadro 5: Componentes das variáveis independentes

\begin{tabular}{|l|c|c|c|}
\hline \multicolumn{1}{|c|}{ Dados a serem coletados durante a pesquisa } & \multicolumn{2}{c|}{ Período } & Campus \\
\hline Indicadores de gestão & 2011 & 2012 & Todos \\
\hline Alunos matriculados por curso e por campus & 2011 & 2012 & Todos \\
\hline Despesas correntes empenhadas & 2011 & 2012 & Todos \\
\hline Despesas de capital empenhadas & 2011 & 2012 & Todos \\
\hline Despesas com pessoal empenhadas & 2011 & 2012 & Todos \\
\hline Outras despesas correntes empenhadas & 2011 & 2012 & Todos \\
\hline
\end{tabular}

Fonte: Elaboração própria.

Os dados dos Quadros 4 e 5 foram obtidos por meio das seguintes fontes: Sistema Acadêmico do IFRN (alunos matriculados), pesquisa de mercado (valor das mensalidades na rede privada de ensino), Sistema Integrado de Administração Financeira - SIAFI 
(despesas) e relatórios internos do IFRN (valores contábeis dos bens móveis e imóveis, como também dos estoques).

Como se pode observar nos Quadros 4 e 5, a coleta de dados da pesquisa tomou como referência os dados gerados no período de 2011 a 2012. O principal motivo que restringiu a quantidade de períodos pesquisados foi a impossibilidade de se obterem dados dos períodos anteriores.

A coleta dos dados foi dividida em duas etapas: uma interna e outra externa. A primeira se desenvolveu nos dezesseis campi do IFRN e na reitoria. Nesses ambientes, foram coletados os dados referentes aos indicadores de gestão de cada campus, informações sobre os gastos realizados por cada um dos campi, os valores dos móveis e imóveis e a quantidade de alunos por cursos. A segunda fase teve como objetivo verificar quais entidades de ensino no estado do Rio Grande do Norte oferecem cursos iguais ou semelhantes aos do IFRN e o valor das mensalidades cobradas por elas.

A Figura 1 é um esquema do caminho percorrido desde o início da coleta dos dados até o momento de se dar um tratamento estatístico a esses dados.

Figura 1: Procedimentos de obtenção e tratamento dos dados

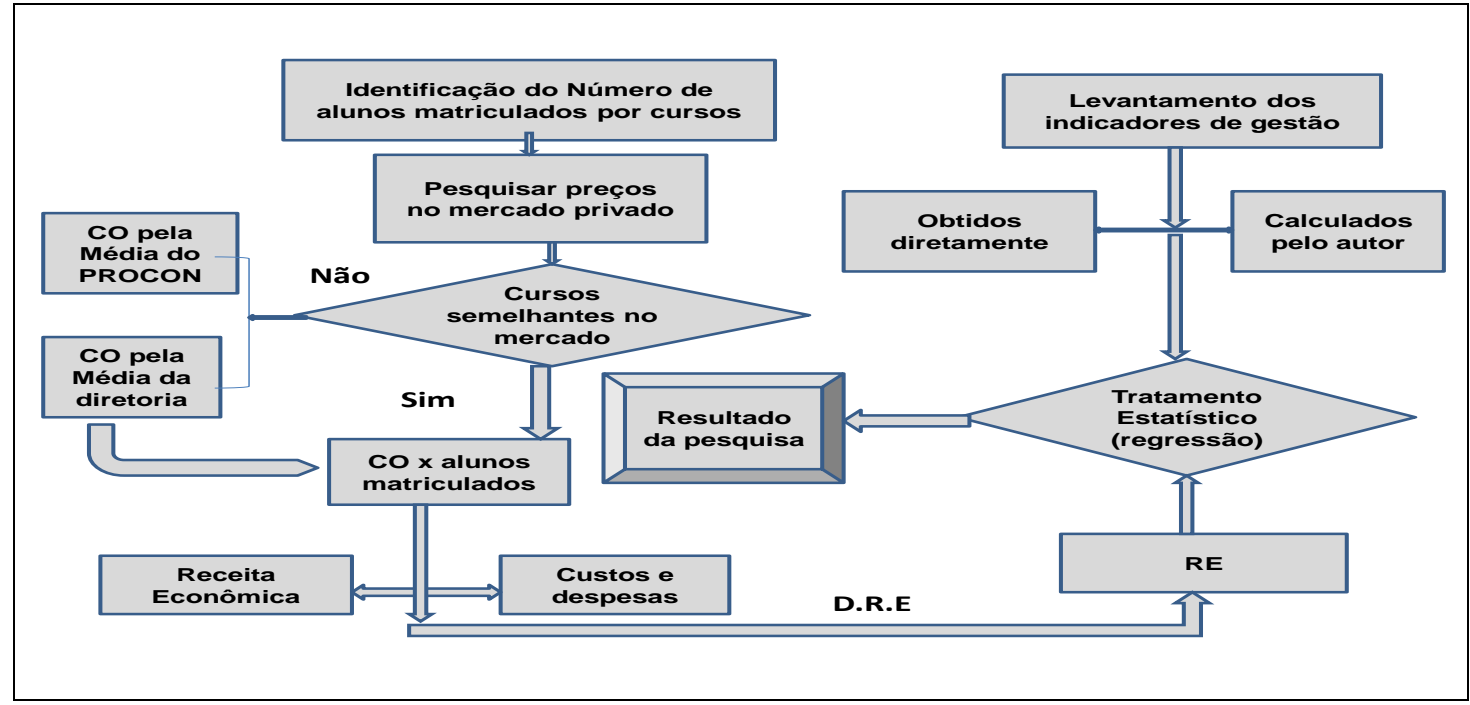

Fonte: Adaptado de Santos (2011).

\section{ANÁLISE DOS DADOS}

Os pressupostos podem ser verificados com a aplicação de testes que têm por objetivo averiguar se a regressão atende às exigências do modelo utilizado. Tecnicamente, a violação 
de cada pressuposto está associada a um determinado problema. Os principais pressupostos para a regressão múltipla são: normalidade, homoscedasticidade e linearidade, segundo Corrar, Paulo e Dias Filho (2012). Por meio dos testes pode-se verificar que os pressupostos da regressão foram atendidos.

Nesta pesquisa utilizou-se a técnica econométrica de regressão múltipla com dados em painel, onde foi aplicado o método dos Mínimos Quadrados Ordinários por meio do software Gretl.

A fórmula representativa da regressão múltipla consiste na Equação 2:

$$
Y=\beta_{0}+\beta_{1} x 1+\beta_{2} x_{2}+\cdots+\beta_{n} x_{n}+\varepsilon
$$

Onde:

Y é a variável dependente;

$X_{1}, X_{2} \ldots X_{n}$ são as variáveis independentes;

$b_{0}, b_{1}, b_{2} \ldots b_{n}$ são os parâmetros da regressão;

$\varepsilon$ é o resíduo ou erro padrão.

Abaixo segue o Quadro 6, com a relação das variáveis independentes e a variável dependente.

\section{Quadro 6 - Descrição das variáveis}

\begin{tabular}{|l|l|l|}
\hline Variável & Descrição & Fonte \\
\hline RE & Resultado Econômico & IFRN \\
RC/V & Relação Candidato/Vaga & IFRN \\
RI/A & Relação Ingressos/Aluno & IFRN \\
RC/A & Relação Concluintes/Alunos & IFRN \\
IRFE & Índice de Retenção do Fluxo Escolar & IFRN \\
RA/DTI & Relação de Alunos/Docente em Tempo Integral & IFRN \\
GCA & Gastos Correntes por Alunos & IFRN \\
PGP & Percentual de Gastos com Pessoal & IFRN \\
PGOC & Percentual de Gastos com Outros Custeios & IFRN \\
PGI & Percentual de Gastos com Investimentos & IFRN \\
ITCD & Índice de Titulação do Corpo Docente & IFRN \\
\hline
\end{tabular}

Fonte: Elaboração própria.

Como pode ser observado no Quadro 6, apenas 10 dos 12 indicadores do relatório de gestão do IFRN foram utilizados na pesquisa. A exclusão dos indicadores Índice de Eficiência (IEA) e Número de Alunos Matriculados por Renda per Capita (A/RP) se deu pela dificuldade de se obterem os dados desses indicadores, o que inviabilizou a utilização dos mesmos.

Tabela 1: Regressão múltipla com dados em painel 


\begin{tabular}{|c|c|c|c|c|c|}
\hline \multicolumn{6}{|c|}{$\begin{array}{c}\text { Incluídas } 15 \text { unidades de corte transversal } \\
\text { Comprimento da série temporal = } 2 \\
\text { Variável dependente: } \mathrm{RE}\end{array}$} \\
\hline Variáveis & Coeficiente & Erro padrão & razão-t & p-valor & G de sig \\
\hline const & $1,34422 \mathrm{e}+07$ & $3,72602 e+06$ & 3,6077 & 0,00176 & $* * *$ \\
\hline RC_V & 15677,8 & 22686,9 & 0,6911 & 0,49748 & \\
\hline RI_A & $-7247,25$ & 11315,5 & $-0,6405$ & 0,52914 & \\
\hline RC_A & -30169 & 11947,7 & $-2,5251$ & 0,02012 & $* *$ \\
\hline IRFE & 31761,8 & 23427,8 & 1,3557 & 0,1903 & \\
\hline RA_DTI & 30640,6 & 8683,11 & 3,5288 & 0,00211 & $* * *$ \\
\hline GCA & $-114,234$ & 102,508 & $-1,1144$ & 0,27832 & \\
\hline PGP & -93288 & 17959 & $-5,1945$ & 0,00004 & $* * *$ \\
\hline PGOC & $-79402,2$ & 36542 & $-2,1729$ & 0,04198 & $* *$ \\
\hline ITCD & $-2,39457 e+06$ & 695291 & $-3,444$ & 0,00257 & $* * *$ \\
\hline Média var. dependente & -2456704 & \multicolumn{2}{|c|}{ D.P. var. dependente } & 1673653 & \\
\hline Soma resíd. quadrados & $1,56 e+13$ & \multicolumn{2}{|c|}{ E.P. da regressão } & 883063 & \\
\hline R-quadrado & 0,808007 & \multicolumn{2}{|c|}{ R-quadrado ajustado } & 0,721611 & \\
\hline$F(9,20)$ & 9,352293 & \multicolumn{2}{|c|}{ P-valor(F) } & 0,000019 & \\
\hline Log da verossimilhança & $-447,2207$ & \multicolumn{2}{|c|}{ Critério de Akaike } & 914,4415 & \\
\hline Critério de Schwarz & 928,4534 & \multicolumn{2}{|c|}{ Critério Hannan-Quinn } & 918,924 & \\
\hline
\end{tabular}

Fonte: Dados da pesquisa.

\subsection{Interpretação dos dados}

Após a realização dos procedimentos estatísticos, obteve-se o modelo de regressão constante na Tabela 5.

Analisando o modelo de regressão encontrado para explicar a questão-problema, percebe-se que existe uma relação inversa entre a variável explicativa, Relação de Concluintes por Alunos Matriculados (RC/A), e a variável dependente, Resultado Econômico (RE). E, ainda que permanecendo constantes as demais variáveis do modelo, a cada variação para mais no indicador (RC/A), estima-se que ocorra uma redução no resultado econômico da instituição. Essa variação acontece, provavelmente, em função de o número de concluintes representar um grupo de alunos que sairão da instituição, causando uma diminuição da receita econômica e, consequentemente, do resultado.

Ao se proceder a análise do indicador Relação de Alunos por Docente em Tempo Integral (RA/DTI), verifica-se que existe uma relação direta entre ele e a variável dependente, onde se observa que, permanecendo constantes as demais variáveis do modelo, a cada variação para mais no indicador estima-se que ocorra um aumento na variável dependente.

Essa observação corrobora com a função do indicador, que mede a proporção de alunos para cada docente em tempo integral. Por causar esse tipo de relação e impacto sobre o resultado, esse indicador pode ser utilizado para medir a eficiência dos gastos com o corpo docente, entendendo que, quanto maior for esse indicador, melhor será o resultado 
econômico. No entanto, ao realizar esse tipo de análise, deve-se tomar cuidado para não se desprezar os critérios de qualidade no ensino, já que índices muito altos de alunos por docentes podem levar à queda na qualidade do aprendizado e, mesmo que no curto prazo essa situação eleve o resultado, pode, no futuro, causar uma evasão por insatisfação dos alunos e, consequentemente, refletir numa baixa da receita e $\mathbf{R E}$.

O Percentual de Gastos com Pessoal (PGP) também se relaciona com o RE de forma inversa, pois, ao permanecer constantes as demais variáveis do modelo, estima-se que ocorra uma redução no $\mathbf{R E}$ a cada variação para mais no PGP.

Os motivos para essa variação podem ser explicados pela relevância da despesa com pessoal no IFRN, cerca de $65 \%$, em média, do total de gastos, e em torno de $77 \%$ das despesas correntes, além do mais, os custos e despesas com pessoal são despesas correntes, que refletem diretamente e negativamente no resultado da instituição.

O percentual de gastos com pessoal é sensível às alterações do RA/DTI e do Índice de Titulação do Corpo Docente (ITCD), devido a esses indicadores se alterarem em função das variações nas despesas com pessoal docente. Percebe-se, na relação entre o PGP e esses dois indicadores, que, caso o ITCD aumente, esse fato causará uma elevação nas despesas com pessoal, o que também ocasionará uma alteração para mais no PGP reduzindo o RE. Caso ocorra uma diminuição no RA/DTI por contratação de professores, esse fato impactará no aumento do PGP, já que a folha de pagamento sofrerá um acréscimo em seu valor ocasionando também redução do RE.

Outro indicador que se apresentou com influência significativa em relação ao resultado econômico foi o Percentual de Gastos com Outros Custeios (PGOC). A relação desse indicador com o RE também é inversa. Dessa forma, ao permanecerem constantes as demais variáveis do modelo, estima-se que ocorra uma diminuição no RE a cada variação para mais no PGOC.

Os Gastos com Outros Custeios (GOC), que incluem todas as despesas e custos correntes exceto os gastos com pessoal, está relacionado aos gastos com a manutenção das atividades do IFRN. São despesas, muitas vezes, difíceis de controlar, pela variedade de itens e alta frequência com que ocorrem. Por se tratar de despesas correntes, impactam direta e negativamente no resultado econômico.

O Índice de Titulação do Corpo Docente (ITCD) influencia o RE também de forma inversa, pois, ao permanecerem constantes as demais variáveis do modelo, estima-se que ocorra uma diminuição no RE a cada variação para mais no ITCD. De acordo com esse indicador, quanto mais o corpo docente da escola se capacita, em nível de especialização, mestrado e doutorado, maior será o impacto negativo no RE da instituição. Apesar de o impacto da evolução desse indicador não ser bom para o RE, essa evolução é sinônimo de melhoria na qualidade da educação, podendo contribuir para o aperfeiçoamento de indicadores que avaliem a qualidade no ensino. Alternativas para conciliar qualidade e custos não são fáceis de encontrar, mas devem ser perseguidas, pois são atributos indispensáveis e inevitáveis no serviço público. 
De uma forma geral, pode-se perceber que os indicadores estão, de algum modo, relacionados entre si, o que sugere que sempre que se for realizar uma análise da forma como eles influenciam o resultado, ela deve ser realizada levando em consideração as variações de cada um deles individualmente e sua relação com os demais.

\section{CONSIDERAÇÕES FINAIS}

O resultado econômico é uma medida de eficiência que indica se uma determinada instituição pública está criando ou destruindo valor para a sociedade. A análise desses indicadores serve de base não apenas para se entender a forma e os motivos das variações no RE, mas, também, a que variáveis o resultado econômico é mais ou menos sensível.

Os gestores públicos, assim como os administradores de empresas privadas, têm necessidade de informações estratégicas que os auxiliem nas soluções dos problemas encontrados no processo de gestão. A administração pública, que normalmente sofre ainda mais com os efeitos da escassez dos recursos econômicos, precisa empregar tais recursos sempre levando em conta a eficiência e a economicidade, para, com isso, poder atender, da melhor forma possível, os anseios da sociedade, que sempre espera das administrações as soluções dos problemas sociais e econômicos, como: saúde, educação, segurança, emprego, dentre outros.

Ao saber que as variações nos indicadores de gestão, que são causadas principalmente pelas decisões tomadas, influenciam no resultado econômico, o gestor público pode utilizar esses indicadores para entender como ocorrem as variações no resultado econômico e, ao mesmo tempo, verificar quais decisões, relacionadas aos indicadores, podem contribuir positivamente na geração de valor para a sociedade. Apoiado por esse tipo de informação, o gestor público tem a possibilidade de economizar tempo e recursos públicos, já que, devido à responsabilidade do cargo que ocupa, precisa sempre ser mais eficiente na utilização dos recursos.

Os indicadores podem servir de guia para se chegar à solução de um problema de forma mais célere. Devido à sua relação significativa com o resultado econômico, o gestor pode analisar qual indicador deve ser melhorado para que essa ação reflita de forma mais relevante no resultado. $O$ gestor pode racionalizar tempo e recursos públicos no processo de gestão, pois tem a possibilidade de agir de maneira mais direta na causa do problema.

A pesquisa também gerou informações sobre o desempenho econômico dos dezesseis campi do IFRN. Com exceção do campus EaD, todos os outros tiveram resultados econômicos negativos, indicando, de acordo com a literatura estudada, que esses campi destruíram valor em vez de gerar resultado para a sociedade.

Apesar de a interpretação do resultado gerado pela grande maioria dos campi indicarem ineficiência e, baseado nesse diagnóstico, autores como Slomski (2009), Mauss e Souza (2008), dentre outros, aconselharem que seria mais viável o governo pagar para os alunos estudarem em escolas privadas, pois a receita econômica calculada por meio do custo 
de oportunidade não conseguiu cobrir todos os custos gerados para ofertar os serviços de educação nos campi do IFRN, é preciso levar em conta a principal limitação da pesquisa, que está relacionada à dificuldade de encontrar instituições de ensino no setor privado que ofereçam cursos semelhantes aos cursos técnicos integrados oferecidos pelo IFRN.

Outro ponto que deve ser levado em consideração para entender os resultados econômicos negativos na maioria dos campi, é o momento de expansão pelo qual o IFRN vem passando atualmente. Essa situação assemelha-se à de uma empresa privada em início de atividade, onde os custos e despesas, principalmente os custos estruturais ou fixos, são bastante altos, enquanto que a receita está apenas no seu início e a empresa ainda precisa atingir, pelo menos, seu ponto de equilíbrio.

Além desses motivos expostos anteriormente, é preciso entender que existem finalidades diferentes na aplicação dos recursos públicos em relação aos privados. Comparar o desempenho econômico de escolas públicas com as escolas privadas pode não ser justo, pelo fato de os setores objetivarem resultados distintos, mas o setor público pode utilizar-se desses parâmetros para buscar a excelência em suas administrações, sempre objetivando os melhores resultados possíveis.

As informações produzidas pela pesquisa podem ser utilizadas para que a gestão do IFRN entenda a importância e a utilidade das informações que já estão disponíveis, como é o caso dos indicadores de gestão, e outras que dependem da implantação de um sistema de informação de custos, para que possa administrar a instituição de forma mais eficiente, agregando valor à sociedade.

\section{REFERÊNCIA}

1. BARCELOS, C. L. K.; SOBRAL, Y. D.; LUSTOSA, P. R. B. Orçamento público gerencial e mensuração do valor agregado: uma abordagem da teoria da gestão econômica. In: CONGRESSO USP DE CONTABILIDADE E CONTROLADORIA, 5., 2005, São Paulo. Anais... São Paulo: USP, 2005.

2. BIO, S. R. Sistemas de Informação: um enfoque gerencial. 2. Ed. São Paulo: Atlas, 2008.

3. BITTENCOURT, F. M. R. Indicadores de desempenho como instrumentos de gestão, auditoria e análise econômica. Revista de Conjuntura, Brasília: Conselho Regional de Economia do Distrito Federal, ano VI, n. 23, jul./set. 2006.

4. BRASIL. Decreto no 5.378 de 23 de fevereiro de 2005. Institui o Programa Nacional de Gestão Pública e Desburocratização - GESPÚBLICA e o Comitê Gestor do Programa Nacional de Gestão Pública e Desburocratização, e dá outras providências. Diário Oficial da República Federativa do Brasil, Brasília, DF, 24 fev. 2005.

5. ___ Lei no 4.320, de 17 de março de 1964. Institui Normas Gerais de Direito Financeiro para elaboração dos orçamentos e balanços da União, dos Estados, dos 
Municípios e do Distrito Federal. Diário Oficial da República Federativa do Brasil, Brasília, DF, 23 mar. 1964.

6. . Lei no 11.892, de 29 de dezembro de 2008. Institui a Rede Federal de Educação Profissional, Científica e Tecnológica, cria os Institutos Federais de Educação, Ciência e Tecnologia, e dá outras providências. Diário Oficial da República Federativa do Brasil, Brasília, DF, 30 dez. 2008.

7. . Ministério da Educação. Secretaria de Educação Profissional e Tecnológica. Manual para produção e análise de indicadores da rede federal de EPCT. Brasília, DF: MEC, 2012. Disponível em: <http://sitesistec.mec.gov.br/index.php? option=com content\&view=article\&id=262\&ltemid=200>. Acesso em: 11 nov. 2013.

8. _ Ministério do Planejamento, Orçamento e Gestão. Secretaria de Gestão. Guia Referencial para Medição de Desempenho e Manual para Construção de Indicadores. Brasília, DF: MP, 2009. Disponível em: <http://www.gespublica.gov.br/ biblioteca/pasta.2010-12-08.2954571235/Guia\%20-\%20Indicadores\%20(versao\%20 preliminar\%20Dez\%2009).pdf/view> Acesso em: 21 set. 2012.

9. _ Ministério do Planejamento, Orçamento e Gestão. Secretaria de Planejamento e Investimentos Estratégicos. Indicadores de programas: guia metodológico. Brasília: MP, 2010.

10. _. Tribunal de Contas da União. Acórdão TCU no 2.267/2005 - Plenário. Aprova medidas junto as Instituições Federais de Educação Tecnológica (IFs) para sanar as discrepâncias encontradas nos dados do Relatório de Análise dos Indicadores de Gestão. Diário Oficial da República Federativa do Brasil, Brasília, DF, 3 jan. 2006.

11. CATELLI, A. O que é Gecon. In: CATELLI, A. (Coord.). Controladoria: uma abordagem da gestão econômica - GECON. 2. ed. São Paulo: Atlas, 2001.

12. CFC - CONSELHO FEDERAL DE CONTABILIDADE. Resolução no 1.129, de 21 de novembro de 2008. Aprova a NBC T 16.2: patrimônio e sistemas contábeis. Diário Oficial da República Federativa do Brasil, Brasília, DF, 25 nov. 2008b.

13. Resolução no 1.133, de 21 de novembro de 2008. Aprova a NBC T 16.6: demonstrações contábeis. Diário Oficial da República Federativa do Brasil, Brasília, DF, 25 nov. 2008c.

14. D`AMORÉ, T. M. Relações entre mecanismos de coordenação e controle com desempenho organizacional: um estudo multi-caso nas instituições públicas de ensino médio de Natal. 2006. 93f. Dissertação (Mestrado em Administração) - Universidade Federal do Rio Grande do Norte, Natal, 2006.

15. DINIZ, J. A.; DIENG, M.; MORAES, E. F.. A utilização de sistemas de custos na administração pública municipal: um estudo sob o enfoque comportamental. In: ENCONTRO DA ANPAD, 32., 2008, Rio de Janeiro. Anais... Rio de Janeiro: ANPAD, 2008.

16. DUTRA, R. G. Custos: uma abordagem prática. 7. ed. São Paulo: Atlas 2010. 
17. FERREIRA, A. Secretaria do Tesouro Nacional, $\mathbf{2 0}$ anos: um marco institucional na história econômica do Brasil. Brasília: STN, 2006.

18. GIL, A. C. Como elaborar projetos de pesquisa. 4. ed. São Paulo: Atlas, 2010.

19. GNISCI, E. F. S. A implementação do Sistema de Informação de Custos no setor público: o caso do governo federal. 2010. Dissertação (Mestrado em Administração Pública), FGV, Rio de Janeiro, 2010.

20. GOMES, E. G. M. Gestão por Resultados e eficiência na Administração Pública: uma análise à luz da experiência de Minas Gerais. 2009. Tese apresentada ao Curso de Doutorado em Administração Pública e Governo da FGV/EAESP. São Paulo, 2009.

21. HANSEN, D. R. MOWEN, M. M. Cost management: accounting and control. 6 ed. São Paulo: Pioneira Thomson Learning, 2009.

22. HOLANDA, V. B.; MACHADO, N. Diretrizes e modelo conceitual de custos para o setor público a partir da experiência do governo federal do Brasil. Revista de Administração Pública. Rio de Janeiro, v. 44, n. 4, 2010.

23. HONDA, A. B. B. Influência do sistema de custos na qualidade do gasto público. Cad. Fin. Públicas, Brasília, n. 11, p. 187-208, dez. 2011.

24. IFRN - INSTITUTO FEDERAL DE EDUCAÇÃO, CIÊNCIA E TECNOLOGIA DO RIO GRANDE DO NORTE. Resolução CONSUP no 31, de 20 de março de 2012. Aprova o Relatório de Gestão e o Processo de Contas do Exercício 2011 do Instituto Federal de Educação, Ciência e Tecnologia do Rio Grande do Norte. Natal: IFRN, 2012. Disponível em: $<$ http://portal.ifrn.edu.br/acessoainformacao/auditorias/

relatorios-de-gestao/relatorio-de-gestao-2011/at_download/file>. Acesso em: 30 jan. 2014.

25. MAUSS, C. V.; SOUZA, M. A. Gestão de custos aplicada ao setor público: modelo para mensuração e análise da eficiência e eficácia governamental. São Paulo: Atlas, 2008.

26. MORAES, E. D. S. O princípio constitucional da eficiência na administração pública: indicadores possíveis. 2007. Dissertação (Mestrado em Direito) - Universidade de Caxias do Sul, Caxias do Sul, 2007.

27. SANTOS, J. J. Contabilidade e análise de custos: modelo contábil, métodos de depreciação $A B C$ - Custeio Baseado em Atividades, análise atualizada de encargos sociais sobre salários. 6. ed. São Paulo: Atlas, 2011.

28. SLOMSKI, V. Controladoria e governança na gestão pública. São Paulo: Atlas, 2009.

29. ; CAMARGO, B. C.; AMARAL FILHO, A. C. C.; SLOMSKI, V. G. A demonstração do resultado econômico e sistemas de custeamento como instrumentos de evidenciação do cumprimento do princípio constitucional da eficiência, produção de governança e Accountability no setor público: uma aplicação na Procuradoria-geral do município de São Paulo. RAP, Rio o de Janeiro, v. 44, n. 4, p. 933-957, jul./ago. 2010. 
SOUZA, E. X.; SANTOS, M. L.; LIMA, A. B.; SILVA, D. B. S.; VICTOR, R. N. Implantação de um sistema de custos no setor público: Um estudo de caso em um hospital de ensino no Nordeste brasileiro. In: SIMPÓSIO DE EXCELÊNCIA EM GESTÃO E TECNOLOGIA. 8., 2011. Resende, RJ. Anais... Resende: SEGeT, 2011. 